\title{
CLASIFICACIÓN ARTESANAL VERSUS CLASIFICACIÓN ÉTNICA. LA HISTORIA NATURAL DEL FOLKLORE DE OTIS MASON Y EL ÁREA DEL FUEGO
}

Joaquín Bascopé Julio ${ }^{1}$

\begin{abstract}
Resumen
Se presenta y discute el olvidado estudio The Natural History of Folklore, publicado en 1891 por el curador estadounidense Otis Mason. Apuntamos, en primer lugar, algunas referencias sobre su actividad intelectual. Luego definimos su clasificación artesanal y la perspectiva política de su ciencia folklórica. A continuación, analizamos un debate sobre las exhibiciones museográficas y clasificaciones etnológicas que explica parcialmente el olvido en que cayó la ciencia de Mason entre los antropólogos académicos. Por último, recuperamos la base nacional y científica de The Natural History of Folklore para testear la validez y vigencia de una de las clasificaciones de Mason: el área de conocimiento tradicional del Fuego.
\end{abstract}

Palabras claves: Otis Mason, Patagonia, Tierra del Fuego, Magallanes, Folklore, Museo, Guaicurú.

\begin{abstract}
The article presents and discuss The Natural History of Folklore, a forgotten study published in 1891 by the curator Otis Mason. First, we offer an outline of his intellectual activity and define his craftwork based classification, as well as the political perspective of Mason's folkloric science. Then, the article introduces a debate about museographic exhibitions and ethnological classification, which partially explains how Mason's science was forgotten by academic anthropology.

Finally, we recover the national and scientific base of The Natural History of

Folklore to test one of Mason's curatorial classifications: the Fuego lore area.
\end{abstract}

Key words: Otis Mason, Patagonia, Tierra del Fuego, Magallanes, Folklore, Museo, Guaicurú.

Recibido: Enero 2015. Aceptado: Junio 2015

\begin{abstract}
Matungo flaco aunque mal criado, jamás olvida el pago. Hombre gordo por bien criado, lo sé, llega a olvidarlo. No busques la diferencia, pa' qué, no viene al caso.

Uno tan sólo animal ha de ser, el otro humano.
\end{abstract}

José Larralde, Diferencia, 1969.

\section{* Introducción}

Otis Tuffton Mason fue un curador e investigador del Museo Nacional de Estados Unidos y del Instituto Smithsonian de la ciudad de Washington. Nació en Eastport, Estados Unidos, el 10 de abril de 1838. Mason descendía de algunas de las familias más antiguas del país. En 1861 se graduó como Maestro en Artes por la Universidad de Columbia y posteriormente obtuvo un doctorado en filosofía y otro en leyes por la misma institución. Sus investigaciones antropológicas comenzaron en el Instituto Smithsonian en 1872, donde comenzó a acomodar las colecciones antropológicas que hasta entonces se hallaban sin clasificar. Se ocupó particularmente del Edificio de las Artes y las Industrias del Museo Nacional estadounidense.

Otis Mason contribuyó además a la historia de las publicaciones arqueológicas y etnológicas. Publicó de manera casi ininterrumpida desde 1874 hasta poco antes de su muerte en 1908. Su último artículo salió de la imprenta el día de su entierro. La mayor parte de sus publicaciones son desconocidas fuera de Estados Unidos.

1 Instituto Patagónico de Ciencias Sociales y Humanas (CONICET-CENPAT), Centro de Estudios del Hombre Austral (Universidad de Magallanes) magallanes@cenpat-conicet.gob.ar. El presente trabajo forma parte del proyecto Fondecyt número 11140027. 
Contribuyó igualmente al desarrollo del diseño antropológico a través de exposiciones en el museo, cursos en la Universidad de Columbia y propagandas de historia natural ofrecidas en las "Charlas de los Sábados", que él mismo organizó en el Museo Nacional.

Junto a otros colegas fundó en 1879 la Sociedad de Antropología de Washington y participó en otras sociedades semejantes que desde entonces afloraron en el país. En 1890 se convirtió en miembro de la comisión nacional de nombres geográficos.

Los estudios de Mason describen y comparan aspectos geográficos y ambientales asociados a industrias primitivas, como las trampas o la cestería. Estuvo interesado especialmente en la historia del transporte y de las comunicaciones en distintas culturas. Su clasificación científica se basó en la invención y en el ingenio de la gente antigua o folk, estudiados de manera comparada.

Una parte importante de los estudios de Mason fue difundida por los medios de comunicación del Instituto Smithsonian y las prensas del gobierno estadounidense, bajo la forma de informes y propaganda científica (panfletos, sin un sentido peyorativo).

En 1889, sus estudios fueron declarados de utilidad pública por el Ministerio de Educación francés. No obstante, ninguna traducción de Mason ha sido publicada en Francia hasta hoy. Tampoco existe ningún texto de Mason en castellano. Cabe agregar, en fin, que La Historia Natural del Folklore, estudio que hemos traducido ${ }^{2}$ y que discutiremos a continuación, tuvo una circulación aún más restringida que sus libros y otros artículos. Estuvo dirigido a curadores, investigadores, artesanos y artistas practicantes de la nueva ciencia folklórica.

\section{* Propaganda Científica nacional}

Cuando Mason publica La Historia Natural del Folklore, en 1891, la antropología estadounidense recién surgía. La situación de Mason tanto en el Museo Nacional, como en

2 La traducción se encuentra disponible en la colección Área del Fuego de la biblioteca digital de la Universidad de Magallanes (www.bibliotecadigital.umag.cl). el Instituto Smithsonian y en las nacientes sociedades de antropología, corresponde al momento en que las ciencias de la cultura se planteaban como hermanas de las ciencias naturales. En este ambiente, Mason promovía que historia, arqueología y folklore debían cruzar experiencias y resultados para obtener un nivel de generalización mayor: la antropología.

Su trabajo consistió en ir clasificando los artefactos que recibía en el museo, como si se tratara de especies naturales. Esta clasificación artesanal o artefactual, responde a una concepción vitalista de la cultura y de la ciencia, practicada todavía por cierta filosofía y sociología históricas (véase El Artesano, Sennet 2009). En antropología, en cambio, predomina la clasificación étnica.

La clasificación artesanal aquí, al igual que la étnica, tiene como trasfondo la expansión territorial de los Estados Unidos, que no sólo permitió la colección de artefactos diversos para el museo, sino una reflexión sobre las artes e industrias de los pueblos colonizados. La clasificación artesanal compara, por ejemplo, el ingenio de los "isleños del Pacífico" malayo-polinesio, constructores de barcos similares en diseño ("craft") a los que se fabrican en las costas del Perú (Mason 1902: 361).

Al seguir el hilo de los inventos y de las adaptaciones de artefactos comparables y ambientes también comparables, la definición de artesanía de Mason incluye tanto a los colonizadores como a los colonizados. Su folklore no es étnico sino nacional. No plantea preguntas sobre la identidad de los pueblos sino sobre las técnicas de fabricación y los ambientes sociales de los artefactos. Propone comparaciones.

Etnia y artesanía se oponen entonces funcionalmente en la ciencia de Mason: la primera es un concepto que distingue y clasifica culturas; la segunda una actividad que generaliza la clasificación cultural a partir de artes e industrias comparables en distintos pueblos.

Dijimos que la ciencia y la clasificación de Mason surgen en medio de la guerra y la conquista de nuevos de nuevos territorios para los Estados Unidos (como las Filipinas a partir de 1899). Pero también, cabe agregar, de la guerra contra los antiguos imperios coloniales (como la guerra contra España por la independencia de Cuba, en 1895). 
En medio de éste ímpetu nacional y guerra generalizada, Mason trabaja en la divulgación de las artes e industrias folklóricas entre la nueva población nacional. La vitalidad de la clasificación artesanal es, en este sentido, inseparable del trabajo de propaganda científica de Mason, desde su posición en el museo nacional con acceso a bibliotecas.

En síntesis, la clasificación artesanal transmite una vitalidad de la cultura inquieta ante el ingenio y la "fuerza de las armas" (Cañas Montalva 1962: 72). La posición de Mason es la de un estadounidense ad portas de que la guerra (1914-1918) produzca una nueva población telecomunicada con cine, $\mathrm{TV}$, radio, etc.

Tal vez por esto la ciencia folklórica de Mason apenas pudo combatir las teorías de mundos psicológicos llamadas "culturas", y representadas en la clasificación étnica. Como analizaremos a continuación, la clasificación étnica permite a un investigador estudiar y defender la particularidad de esta o aquella cultura. Esta antropología disocia el ambiente de la población, y por ello se aleja de la generalización, característica de la clasificación artesanal. Cierta trascendencia de la cultura, coincidente con el crecimiento de la antropología universitaria y de un notable campo académico de debates culturales, se dieron en paralelo.

Hablamos de propaganda científica, entonces, pues para Mason la antropología todavía no existía. Circulaban ideologías distintas, con medios de expresión también diversos, sobre el porvenir de esta ciencia. Y era pertinente debatir al respecto.

En la clasificación artesanal de Mason la antropología sería un nivel de generalización deseable, que se alcanzaría por el trabajo compuesto de varias ciencias. Este trabajo resultaría en un conocimiento que sólo podría exponerse, divulgarse, una vez recorrido el camino natural de toda ciencia:

"Para comprender la verdadera posición del folklore en las ciencias que van a componer la antropología, recuerden simplemente que estamos conectados con el pasado de nuestra raza tanto como con su presente. Existen tres volúmenes que registran esta conexión: aquél que está escrito en las cosas, aquél que se preserva en documentos y aquél que llega a nosotros a través de los dichos y las costumbres. La ciencia que investiga el primer volumen es la arqueología, el segundo es la historia y el tercero, para cuyo estudio ningún nombre ha sido ideado, es el folklore" (Mason 1891: 97).

El objeto de esta ciencia compuesta consideraba a la gente antigua o tradicional (los folk), pero también a los propios investigadores: todos devenimos folk "cuando somos anticuados" (Mason 1891: 97). El argumento era simple: la antropología americana se formaría en el conocimiento de su historia natural y humana, en el conocimiento de la geografía y del clima donde surgen el invento, el dicho o la costumbre. Se trata de un conocimiento distinto al conocimiento tradicional, aunque originado en él y mejorado por el método científico:

"El folklore es cristaloide; la invención y la ciencia son coloidales. El folklore se mantiene vivo por la opinión pública y es lo opuesto al progreso; la invención y la ciencia son centrífugas, azarosas, individuales" (Mason 1891: 98).

En la propaganda cientifica de Mason, la antropología debía convertirse en el conocimiento tradicional de la raza americana. En tanto curador e investigador, trabajó transmitiendo el folklore, o "la antropología que posee la gente tradicional" (Mason 1891: 103), a los distintos ámbitos de su presente. Mason escribió él mismo panfletos que circularon en entre académicos y no científicos, sobre la manera de colectar objetos antiguos. Pero más allá de las iniciativas individuales, los medios masivos para la transmisión de la antropología pasaban por el museo y la biblioteca.

El rol del museo y de la biblioteca, en tanto medios de divulgación, eran y siguen siendo decisivos para la propagación de la antropología como conocimiento tradicional. En lugar de aislar a los pueblos colonizados en un reducto, Mason pensaba en la transmisión de la historia y la cultura a la población. Explotó el rol popular que cumple el museo y la biblioteca en una nación joven y en expansión. Así, la "propaganda científica de Mason se iría convirtiendo en programa político a medida que fuésemos "descubriendo las características en las cuales se basará una clasificación nacional y científica" (Mason 1891: 100). 
Para situar históricamente a Otis Mason, debemos sustituir la imagen del folklorista nostálgico del pasado por la del investigador entusiasmado con el presente, inquieto con la nueva realidad electro mecánica de su país, ocupado del rol político y pedagógico de la ciencia y de la información transportable y tele-comunicable para divulgarla.

La figura de Mason es comparable a un contemporáneo suyo, Isabelo de los Reyes, folklorista ilocano y activista político filipino, quien, un año después de la independencia de su país, publicó El Folklore Filipino. Allí se incluye una lista de supersticiones introducidas por los católicos a Filipinas y asumidas luego como tradiciones indígenas por los folkloristas españoles contemporáneos a Isabelo de los Reyes (Anderson 2005: 7-25).

Esta versión política del folklore, en tanto antropología de la gente antigua y en tanto conocimiento transmisible por medios de comunicación, sigue siendo proclive a la formación de inteligencia política en pueblos colonizados. Los movimientos indígenas nacionales, que cuentan hoy en sus filas con estudiosos del pasado, pero también cualquier investigador regional que afirme una unidad entre memoria y territorio frente al multiculturalismo capitalista y al conocimiento académico transnacional, podrían verse reflejados tanto en la clasificación artesanal de Mason como en su práctica de propaganda científica.

Pues el conocimiento tradicional reelaborado a través de la ciencia, y transmitido a la población a través de medios como la biblioteca o el museo, era la perspectiva de cualquier folklorista, entonces, si asumía simplemente que estamos conectados con el pasado de nuestra raza tanto como con su presente.

\section{* El problema de la clasificación: Mason Versus Boas}

Para responder la pregunta de por qué las acciones y las ideas documentales y museológicas de Mason cayeron en desuso con el desarrollo antropológico del siglo XX,

3 La primera edición de El Folklore Filipino se publicó un año antes de la Historia Natural del Folklore de Mason, en 1890. Allí no hemos hallado los pasajes citados por Anderson (2005) por lo que suponemos que Isabelo de los Reyes los agregó en una segunda impresión. es pertinente considerar su debate con Franz Boas, a menudo considerado el padre de la antropología americana. ¿Por qué dichas acciones e ideas dejaron de emplearse si el mismo Boas, en su cariñoso obituario a Mason, escribió que éste había ejercido una "saludable influencia en el desarrollo de la antropología" y que "sus trabajos le aseguran un lugar permanente en la historia de la antropología"? (Boas 1908:362).

Ocurre que la visión de la ciencia de Mason se oponía radicalmente a la de Boas. Mientras aquél siguió los pasos de las ciencias naturales, en el sentido de la colecta y la clasificación sin apurar el momento de la generalización, Boas desechó este camino y se fue concentrando, cada vez más, en el particularismo de cada cultura.

El debate entre Mason y Boas se dio concretamente respecto de la generalización o particularismo aplicado a exhibiciones en museos populares. El debate se publicó en la revista Science en 1887. Se trató, sin duda, de un debate vanguardista, vista la situación de la antropología entonces, y por la misma razón no encontró mucho eco. El debate fue redescubierto en 1957 por John BuettnerJanusch, quien lo transcribió parcialmente y los publicó con sus propios comentarios, que nosotros transcribimos y traducimos parcialmente a continuación.

Tal vez por su juventud, y a pesar de los veinte años que le sacaba Mason, Boas discutía con convicción: "Nuestra objeción a la idea de Mason es que clasificación no es explicación" (Boas 1887a: 485). Para precisar esta objeción, Boas recurrió a la metáfora musical:

"De una colección de instrumentos de cuerda, flautas o percusión de tribus "salvajes" y de la orquesta moderna, no podemos derivar ninguna conclusión salvo que medios similares han sido empleados por distintos pueblos para hacer música. El carácter de sus músicas, el único objeto que merece ser estudiado pues determina la forma de los instrumentos, no puede entenderse a partir de un sólo instrumento, sino que necesita un colección completa de una sola tribu" (Boas 1887a: 486).

Es difícil entender lo que Boas pretende significar aquí, sin embargo, el carácter místico y anti-científico de su planteamiento es evidente. Ninguna ciencia puede aspirar a conocer el número total de variaciones de sus 
objetos, pues no es ése el espíritu de quien clasifica o de quien monta una exposición en un museo.

Mason le respondió rápidamente, indicando que tanto los curadores de museos como quienes clasifican especímenes etnológicos lo hacen aplicando varios principios de clasificación. Éstos dependen tanto del objetivo de nuestra exhibición como de los límites de nuestras colecciones de artefactos. Mason confirmaba simplemente una de las bases de la interpretación científica, a saber: que las especies exhibidas adquieren sentido ante el público en un contexto particular y que un artefacto puede tener tantos sentidos como contextos en los que pueda aparecer.

La importancia de este debate en la historia de la antropología se aprecia mejor cuando Mason y Boas llegaron al tema de los inventos y del ingenio artesanal presente en cada pueblo. Para Mason, inventos similares surgían en ambientes geográficos y culturales similares. Boas, sin embargo, creía que esto era tan cierto como lo contrario, que efectos similares surgen por causas disímiles. Mason consideró la idea de Boas como una "sugerencia muy ingeniosa" pero que, sin embargo, nada tenía que ver con lo que se estaba debatiendo:

"Salvo de una manera muy general, su afirmación de que efectos similares proceden de causas diferentes apenas puede encontrar aceptación, frente al axioma de que 'efectos semejantes surgen de causas semejantes' " (Mason 1887: 534).

Según Boas, Mason pretendía "sacar conclusiones por analogía", mientras que él se jactaba de emplear un "método inductivo". Lo que hacía Boas en realidad era confundir generalización y analogía. Es decir, confusión entre la extracción de las propiedades de un fenómeno para construir una categoría, con el proceso de hacer analogías propiamente tal. Así, en lugar de considerar que los principios y las leyes que rigen el surgimiento de tales o cuales inventos o adaptaciones del hombre al ambiente (que siempre son creación de los científicos o de los curadores según los fines de la exposición y los límites de la colección), Boas afirmaba que dichas leyes eran "leyes fisiológicas" y que un antropólogo las podía "encontrar" (Boas 1887b: 588). Esta es una idea de la ciencia que, ayer como hoy, tiene pocos adherentes.

El debate Mason versus Boas se desvió a continuación por la intervención en la revista del famoso soldado y antropólogo John Powell, quien no se ocupó del asunto de las semejanzas e inventos, sino de la imprecisa clasificación etnológica de Boas. Powell consideró como lo más razonable para la clasificación la clasificación artesanal de Mason. Boas le respondió que esto llevaba a "hacer clasificaciones artificiales". Que la idea de Mason daba pie a fabricar muchas réplicas de objetos, a sobrecargar las colecciones y confundir las etnias. Que la mejor clasificación, en fin, era "agrupar las tribus de acuerdo a sus similitudes étnicas" (Boas 1887c: 624). Y así concluyó el debate.

Como enfatiza John Buettner-Janusch, Boas no sólo no cambió su actitud anti-científica sino que la profundizó, a pesar de que, desde un comienzo, iba en contra de la opinión de la mayoría de los antropólogos y científicos
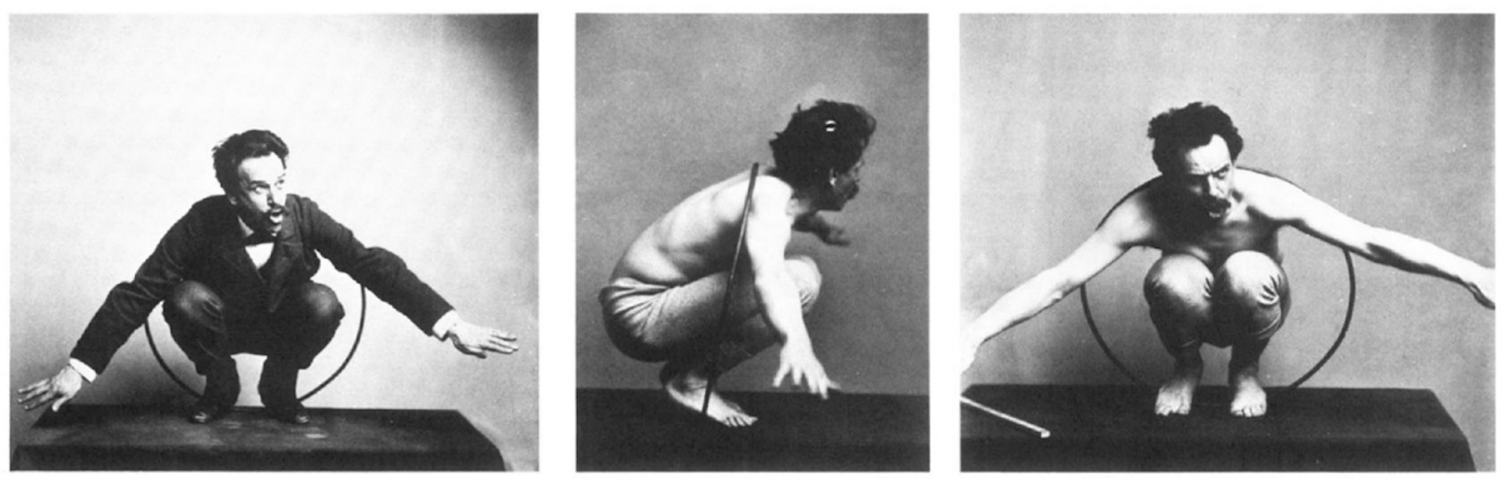

Figuras 1, 2 y 3. Franz Boas posando como un espíritu caníbal para un diorama en el Museo Nacional de Washington. Fotos conservadas por Otis Mason (Hinsley y Holm 1976:308) a pesar de la solicitud de Boas para que las destruyera (Abel 1977: 442). 
destacados de su época como Planck, Poincaré o Einstein. Por lo mismo, coincidimos en que "es irrelevante si la personalidad de Boas es la de un árbol frutal o la del líder de un culto", pues es en las "fuerzas socioculturales" y las "ideologías" de su tiempo donde corresponde ubicar el debate (Buettner-Janusch, 1957:322-323).

Sabemos que en tiempos de Mason otras naciones americanas se encontraban, al igual que Estados Unidos, ocupando militarmente territorios indígenas. En estos territorios surgieron folkloristas con preguntas autónomas sobre la memoria y la cultura de los colonizados. Pueblos que se iban clasificando como folk en institutos nacionales como el Smithsonian (o en museos como el de Washington o el de ciencias naturales de La Plata ${ }^{4}$ ). Estos investigadores folk compartían y comparten medios de comunicación semejantes (imprenta, fotografía, tren, etc.) con los ambientes académicos europeos. Pero entre el medio folk y el medio académico hay una diferente comprensión de la ciencia natural. El medio folk comprende un ámbito de interacción con otros colegas investigadores, pero ubica la relación entre el investigador y su audiencia en una misma mentalidad científico natural. La mentalidad académica es distinta en este punto: su audiencia son otros académicos. El científico folk, en cambio, es un "historiador de la mente humana" (Mason 1891: 105), indisociable de la audiencia y del área de conocimiento tradicional en la que ambos surgen. En antropología, se da a menudo el caso del científico folk que se transforma en informante del académico, escritor o documentalista (Pavez 2003).

Quizá por esta diferencia entre ciencia folklórica y académica, las clasificaciones de Mason tuvieron menos eco en Europa y América que las de Boas. El pensamiento boasiano se transfirió de vuelta al medio académico europeo y generó importantes discusiones a lo largo del siglo XX. Generó tantos seguidores y tantos críticos que constituyó todo un falso campo científico en el que la antropología sigue inmersa. Esto se confirma en el hecho de que el pensamiento boasiano acabó constituyendo un ámbito de estudios académicos (véase Stocking 1966). Para entonces la historia de la antropología se había convertido ella misma en un tema de reflexión, en revistas pioneras como American Anthropology, con las que Mason había originalmente cooperado 5 .

\section{* Clasificación artesanal versus personal TÉCNICO}

Considérese el campo de estudio de cosmogonías americanas abierto por el notable antropólogo francés Claude Lévi-Strauss -quien fuera entrenado por Boas pero, sorprendentemente, nunca supo de Mason.

En su artículo "La estructura de los mitos" (1955), Lévi-Strauss invocó una nueva inteligencia para estudiar relatos cósmicos de indios, pero no tenía claro cómo se fabricaría esa inteligencia. Y en el intento de explicarla, complicó las cosas. "La estructura de los mitos" arranca con un homenaje a Boas, colocando en epígrafe una frase de su introducción a las Tradiciones de los Indios del Río Thompson de Teit (1898: 18): "Se diría que los universos mitológicos están destinados a ser pulverizados apenas formados, para que de sus restos nazcan nuevos universos".

4 El museo de la Plata surge en el marco del "proyecto pedagógico y conservacionista" del investigador autodidacta Francisco Moreno -fundador y director vitalicio del museo. Moreno planteó la nacionalización del vasto territorio ganado al indio patagónico a través de parques naturales. La aplicación museológica de su proyecto se comprende en el ambiente electro-mecánico de tarjetas perforadas (imprentas, fonógrafos, films) y de telecomunicación con que se renovó la ciencia de entonces. En este ambiente se movieron destacados exploradores e investigadores. En este mismo ambiente electro-mecánico surgió y se propagó, paralelamente, el rifle a repetición con el que se fue desalojando a los antiguos ocupantes de los nuevos parques nacionales argentinos. Se trata, en fin, de un ambiente científico conectado a "los valores fundacionales del sistema estadounidense", no sólo de parques nacionales, como planteó Navarro Floria (2008:2), sino del sistema estadounidense de despojo de territorios indígenas, y de registro y exhibición del pasado del colonizado. Desde su fundación en 1884, el museo de ciencias naturales de La Plata cumple un rol fundacional del pasado indio de la Argentina.

5 No encontramos ninguna referencia a Mason en compilados estadounidenses clásicos de historia de las representaciones etnográficas, de las clasificaciones etnológicas y de las exhibiciones antropológicas en museos (por ejemplo, Clifford y Marcus 1986, y Clifford 1988). 
Ya en el texto, Lévi-Strauss retomó la metáfora de la orquesta boasiana para explicar la necesaria inteligencia mitológica. ${ }^{6}$. Pero en lugar de mejorar la perspectiva psicológico intelectual del mito, como anuncia al comienzo, oscureció el panorama proponiendo una nueva sociología de los mitos. Así, en la conclusión del artículo se plantea un falso obstáculo:

6 "Imaginemos unos arqueólogos del futuro, llegados de otro planeta cuando ya toda vida humana ha desaparecido de la superficie de la Tierra, que excavan en el lugar donde estaba emplazada una de nuestras bibliotecas. Estos arqueólogos ignoran todo lo referente a nuestra escritura, pero tratan de descifrarla, lo cual supone el descubrimiento previo de que el alfabeto, tal como nosotros lo imprimimos, se lee de izquierda a derecha y de arriba hacia abajo. Sin embargo, una categoría de volúmenes permanecerá indescifrable de esta manera. Serán las partituras de orquesta, conservadas en el departamento de musicología. Nuestros sabios tratarán sin duda, encarnizadamente, de leer los pentagramas uno tras otro, comenzando en la parte superior de la página y tomándolos en sucesión; luego, advertirán que ciertos grupos de notas se repiten con ciertos intervalos, de manera idéntica o parcial, y que ciertos contornos melódicos, alejados en apariencia unos de otros, presentan entre sí analogías. Tal vez entonces se preguntarán si estos contornos no deben ser tratados como elementos de un todo, que es necesario aprehender globalmente en lugar de abordarlos en orden sucesivo. Habrán descubierto entonces el principio de lo que llamamos armonía" (Lévi-Strauss 1958: 234). La suposición de que la ciencia de la cultura requiere descifradores es una especie de culto al espíritu de la cultura (de la música en este caso), recurrente en Boas y Lévi-Strauss, que todavía subsiste en ciertos ambientes intelectuales, como el ejército o la masonería. Este tipo de pensamiento encriptado o anti-científico podría denominarse "a-masónico", en referencia al olvidado curador del Smithsonian.
"Las condiciones precarias de la investigación científica en Francia no permiten por el momento, desgraciadamente, llevar más adelante el trabajo. Los textos míticos son extremadamente voluminosos. Su análisis en unidades constitutivas exige un trabajo de equipo y un personal técnico. Una variante de dimensiones medias proporciona varios cientos de tarjetas. Para descubrir la mejor distribución de esas tarjetas en columnas e hileras, sería preciso contar con clasificadores verticales de 2 metros por 1,50 aproximadamente, con casilleros que permitan repartir y desplazar las tarjetas a voluntad. Y a partir del momento en que se intenta elaborar modelos de tres dimensiones, para comparar un cierto número de variantes son necesarios tantos clasificadores como variantes haya, así como también un espacio suficiente para moverlos y distribuirlos libremente. En fin, si el sistema de referencia exige más de tres dimensiones (lo cual tiende a producirse rápidamente, como lo hemos indicado en la página 242), será necesario recurrir a las tarjetas perforadas y la mecanografía. Sin esperanza de contar, por el momento, ni siquiera con los locales indispensables para la constitución de un solo equipo, nos contentaremos con presentar tres observaciones, a modo de conclusión" (Lévi-Strauss 1958: 253-254).

El supuesto problema de Lévi-Strauss (las precarias condiciones de investigación francesas) no era, evidentemente, técnico o de falta de espacio. Tampoco se trata

7 Agradezco a Martín Bowen Silva la referencia a la obra de Kircher.
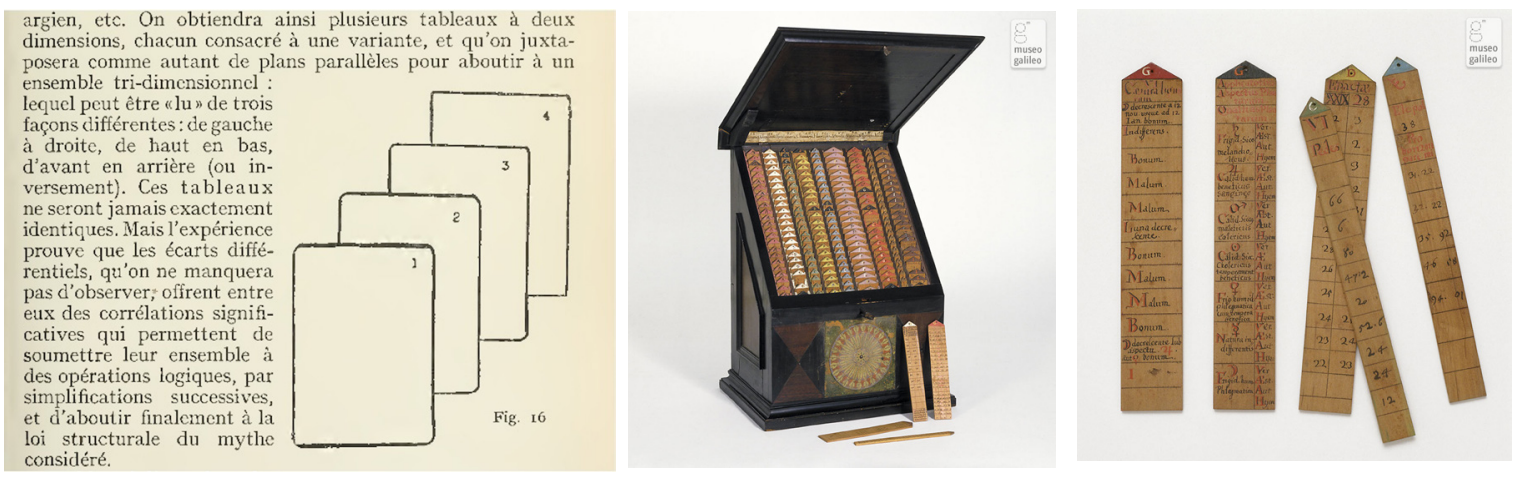

Figuras 4, 5 y 6. Texto y tarjetas para obtener la "ley estructural del mito" (de la página 242). Abajo: el Organum Mathematicum y sus tarjetas, diseñados por Gaspar Schott -ayudante del intelectual jesuita Athanasius Kircher- en 1668

(gentileza del Museo Galileo, Florencia) ${ }^{7}$. 
de un problema nacional, de la investigación en Francia. Una operación más simple nos muestra que el problema de Lévi-Strauss era otro: basta contar las referencias a Boas en sus artículos.

La influencia de la orquesta boasiana, o bien, de las fuerzas socioculturales e ideológicas subyacentes a dicha orquesta, hicieron de Boas un árbol frutal y el líder de un culto para el propio Lévi-Strauss. Nos referimos también a sus críticas o diferencias con Boas. En Antropología Estructural hay por lo menos veinte referencias directas a Boas. Ninguna a Mason, como puede anticiparse. Tampoco encontramos a Mason en los otros libros de Lévi-Strauss. Y, sin embargo, Mason escribió lo siguiente:

"El conocimiento tradicional de un pueblo, de una región, de una raza, incluye todo el ámbito de las ciencias antropológicas, consideradas desde el punto de vista de ese pueblo, región o raza. En la misma línea, el conocimiento tradicional del mundo expande el panorama a todos los tiempos y climas. Aquellos que investigan el tema con esta concepción en mente, toman hasta los infimus conceptus, como las fórmulas de echar a suertes, y buscan todos los ejemplos que existen bajo del sol al respecto ${ }^{8}$. Para las distintas áreas de conocimiento tradicional, me imagino a menudo una especie de tarjetas con cuadrículas, con los conceptos clasificatorios de la ciencia antropológica en la columna vertical y los objetos de pensamiento folk y de costumbres folk ubicados arriba en la horizontal. En cada cuadro el recolector, a través de un número o una referencia, podría indicar el carácter de la respuesta folle a este concepto binominal. Todo lo que el señor Bolton ${ }^{9}$ y otros trotamundos del folklore tendrían que hacer sería darle un vistazo al cuadro completo y ver si nos hemos olvidado algún ejemplo. Mejor aún, estos infatigables caballeros podrían ser instados para rellenar muchos de nuestros cuadros vacíos. El mundo se transformaría entonces en una enciclopedia folklórica" (Mason 1891: 105).

La clasificación científica de Mason y de Lévi-Strauss coincide solamente en el soporte (especie de tarjetas). Puestas en serie, las tarjetas con cuadrículas binominales de aquél o las tarjetas perforadas de éste, podrían ser la cinta magnetofónica en el primer caso y el rollo de film en el segundo. Es decir, los soportes del conocimiento tradicional, del folklore del radiofonista, del cineasta o del videasta del siglo XX. También es el conocimiento tradicional surgido en la relación entre éstos y los auditores y televidentes. El conocimiento que va en los artefactos de transmisión de mensajes, en tanto soportes, y el conocimiento generado en cada evento de rememoración y/o representación del pasado. El mito es también la audiencia que estimula, o no, al narrador o narradora.

Existe una conexión entre la clasificación artesanal de Mason y el ambiente geográfico y social al cual refiere dicha clasificación, que se rompe en las clasificaciones etnológicas de Boas y en las reducciones mitológicas de Lévi-Strauss. Este último creyó necesitar personal técnico y espacio suficiente para sus clasificaciones. Algo muy semejante, en todo caso, a un computador con respectivas clases, códigos o lenguaje de programación. Verdadero "anuncio del fin de las contradicciones del humanismo" (Anales de Desclasificación 2005: 47). Así podría definirse esta necesidad levistraussiana de clasificadores y casilleros exclusivos para los mitos, desconectados entonces, necesariamente, del artefacto y de la costumbre ${ }^{10}$. Bajo esta necesidad, el mito entendido como actividad de memoria y entretenimiento ante una audiencia determinada, quedaría resumido y ordenado en el clasificador cibernético de registros del antropólogo ${ }^{11}$. Sabemos, no obstante, que la imagen del personal técnico trabajando

8 En "La estructura de los mitos", Lévi-Strauss imagina un etnógrafo trabajando en la consulta de una tarotista, observando a sus clientes por un período prolongado y de manera semejante a "como lo hacemos nosotros con nuestros informantes indígenas" (Lévi-Strauss 1958: 235).

9 Henry Carrington Bolton (1843-1903) fue un químico y bibliógrafo de la ciencia.

10 Mason consideró que esa desconexión era un impedimento para la investigación: "El arqueólogo que revuelve un cerro, el paleontólogo que remueve un fósil de los restos a los que está asociado, el anatomista de un animal extraño que destruye las conexiones entre sus partes, todos ellos han cerrado la puerta de la investigación. El gabinete folklórico, en cambio, es como los montones de atlas enumerados en la oficina del Censo. El material está siempre a mano para ser reconsiderado" (Mason 1891: 99).

11 Se trata de una especie de culto clasificatorio académico que tuvo una expresión concreta en la serie Folk Literature of South American Indians, dirigido por Johannes Wilbert y Karin Simoneau, publicada en veinticuatro tomos entre 1970 y 1992 , y en cuya clasificación y codificación se empleó al cibernético Yehuda Afek. El proyecto se desarrolló en una universidad californiana, donde Afek estudiaba antropología, y ocurrió en paralelo al surgimiento, en esta misma región, de la economía cibernética empleada hoy tanto en el mundo de la industria como en el de las artes, la comunicación o las técnicas de gobierno. 
en locales aptos para clasificadores y casilleros es un sueño logístico realizado muchas veces y por distintos medios. En el film propagandístico Avatar (2009), por ejemplo, una etnia de gigantes es invadida por un equipo de diminutos militares y científicos quienes trabajan como personal técnico levistraussiano, es decir, en una sala con espacio para la clasificación étnica en varias dimensiones y en donde codifican y replican la inteligencia nativa, la cual creen está enredada al territorio invadido tal como las neuronas se conectan en el cerebro. Siguiendo estos cultos a la clasificación étnica, la antropología pareciera una armazón lógica o un logotipo académico, antes que un conocimiento en el sentido de Mason, compuesto de historia, arqueología y folklore. Y nada más folklórico, por otra parte, que la "tecnología" que un antropólogo supone como necesaria para su ciencia.

Cabe agregar que cuando Lévi-Strauss escribió sobre su necesidad de clasificadores y de series de tarjetas perforadas para los mitos (1955), hacía veinte años que Walt Disney había estrenado Blancanieves y creado el Pato Donald. Luego vinieron Pinocho, Bambi, La isla del tesoro, La cenicienta y el ratón Mickey. Industria mítica, impresa en rollos de film perforados.

Mientras Lévi-Strauss creía que el problema del estructuralismo, de la teoría a fin de cuentas, era la precariedad científica francesa, las series de tarjetas perforadas con mitos, idénticas a un rollo de film, eran fabricadas en Estados Unidos (donde Lévi Strauss enseñaba). También se produjo arte folk en el terreno donde Lévi-Strauss levantó su data (las regiones selváticas del Brasil). Y también en su medio académico nacional, Paris, donde un año después de "La estructura de los mitos" tuvo lugar el Primer Congreso de Escritores y Artistas Negros. A este congreso Lévi-Strauss dirigió especialmente una carta de amistad.

Esta derrota parcial de las clasificaciones etnológicas ocurrió igualmente en otras áreas de conocimiento tradicional americano, además de en casa de Boas y de LéviStrauss: mientras ellos hacían antropología, los pueblos étnicamente clasificados se fueron apropiando de dichas clasificaciones y produjeron nuevas industrias culturales ${ }^{12}$. Nuevos folklores.

De las tarjetas perforadas surgieron, cabe agregar, in- dustrias y artesanías distintas a Disney. Otro tipo de folklore, de arte de la memoria y de música regional, que se aprecia en obras como Deus e o Diablo na Terra do Sol (Glauber Rocha 1964). Al producirse junto con una audiencia concreta, la industria folklórica se opone al clasificador cibernético de mitos que esperaba Lévi-Strauss. Este nuevo folklore americano no es una logia académica del mito, sino aquel arte que desafía la mitología con nuevas producciones (un buen ejemplo es la performance Herencia pa' un hijo gaucho de José Larralde 1968):

"Cada dios y cada espíritu menor es una copia de algo real. La mitología sólo es una parte del folklore y sólo puede ser comprendida cabalmente cuando tenemos un entendimiento correcto del plano cultural del narrador del mito y de su audiencia" (Mason 1891: 103) ${ }^{13}$.

Por esta razón, la imaginación de Mason y Lévi-Strauss, en los párrafos citados, coinciden sólo en el soporte: mientras aquél pensaba en la tecnología para transmitir el folklore a una población emergente, éste la solicitaba para seccionar y especializar el conocimiento tradicional entre académicos ayudados por personal técnico o computadores para clasificar.

El conocimiento de "La estructura de los mitos" difícilmente puede transmitirse a un estudiante sin entrenamiento en filosofía o teología. Como se advierte, los artefactos (libros incluidos) que conectan el conocimiento tradicional antiguo con el moderno, y lo transmiten a través de la biblioteca o del museo, son distintos al

12 "Ante el anuncio del fin de las contradicciones del humanismo [de Lévi-Strauss], por la incorporación de sus clases más bajas, resurge el ruido estructural de un proletariado que se resiste a ser el último, a avalar el fin de la historia que empezó sin él. [...] Con el advenimiento del "último humanismo", la klassis griega se extiende al mundo entero. Se establece por fin la perfecta convergencia, el matrimonio sin resto de una topología y una nomología clasificatoria universal. Ante semejante derrota sólo queda la desclasificación de negros que escriben, de Medinas [José Toribios] que mueren, de humanismos que quieren ser otros" (Anales de Desclasificación 2005: 47).

13 Consúltese al respecto el diario de campo de cualquier producción audiovisual que narre la colonización de América. Estos diarios constituyen materiales preciosos para la ciencia folklórica del siglo XXI. Véase, por ejemplo, el extraordinario diario del film Fitzcarraldo (1982) en Herzog (2012). 
personal técnico para clasificar mitos que reclamaba LéviStrauss. El conocimiento tradicional colectivamente reconstruido al que accedemos hoy a través de internet, se asemeja más bien al mundo vuelto enciclopedia folklórica que imaginó Mason.

Por último, a pesar de los debates psicológico intelectualistas que señalamos, la investigación antropológica, en tanto ciencia compuesta de historia, arqueología y folklore, ha sobrevivido en otras humanidades (como la filosofía y la sociología histórica), distintos de la etnología académica euroamericana. Esta ciencia sigue basándose en la transmisión de conocimientos tradicionales a la población moderna ${ }^{14}$.

En la siguiente sección presentaremos una de las áreas de conocimiento tradicional (lore areas) que propuso Mason para el continente americano, basándose en la clasificación artesanal.

\section{* El área del fuego}

Para representar de mejor manera las diferencias científicas y políticas entre la clasificación artesanal y la clasificación étnica, nos concentraremos en las áreas de conocimiento tradicional de Mason que se conectan con nuestras investigaciones. Se trata de las áreas "del Fuego" y "Patagonia argentina", las últimas de las dieciocho áreas con las que Mason fue etiquetando los artefactos almacenados en el Instituto Smithsonian ${ }^{15}$.

Ya referimos el olvido general en el que cayó Mason, a diferencia de la antropología boasiana y de los sucesores más o menos críticos de Boas. La tensión entre clasificación étnica y clasificación artesanal se desarrolló tempranamente en el área fuego patagónica, como se aprecia en Manners and Customs of the Firelanders (Bridges 1866). Este fue uno de los primitivos estudios, elaborado en paralelo a diccionarios, mapas, ilustraciones y diarios de viaje - entre otros materiales - en la estación experimental de la isla Keppel (Falkland/Malvinas). Tal como una industria cultural en nuestros días, la estación de Keppel fue una potente imprenta anglo-fueguina que documentó tempranamente el área de conocimiento tradicional de Fuego.

Es decir, antes de que Mason le diera el nombre de "Fue- go" al área desde su oficina sub-ártica en el instituto Smithsonian. Y antes de que desembarcaran en nuestra región los antropólogos de Buenos Aires o de Santiago de Chile, para clasificar cada etnia según el pasado nacional respectivo.

Así, a pesar del avance de las antropologías nacionales en paralelo a la colonización ${ }^{16}$, la clasificación artesanal masónica en Fuego Patagonia no cayó en el olvido, como sí ocurrió en la academia metropolitana. Mason y sus contribuciones aparecen referidos en la notable bibliografía de las tribus fueguinas de Cooper (1917: 111) ${ }^{17}$.

14 El intercambio de Mason y Boas en torno a la clasificación y la transmisión del conocimiento, tuvo una actualización reciente en la revista Brain and Cognition, con dos investigadores discutiendo el concepto y la clasificación neuroeléctrica versus la clasificación artesanal (véase Sammar 1995).

15 Estas áreas no fueron una creación de Mason, sino el resultado de la coordinación de distintos trabajos de la Oficina de Etnología Americana, del Museo Nacional y del Instituto Smithsonian.

16 La fulminante colonización del territorio fuego patagónico creó, ideológicamente, una especie de área de culto al indio en vías de extinción, gracias a misioneros y sacerdotes-antropólogos, afines al pensamiento boasiano. Entre ellos destaca el verbita Martín Gusinde. Sobre su imaginación mística y la red científica en que operó, conocemos los estudios críticos de Prieto y Cárdenas (1999) y Pavez (2012). Sobre el pensamiento fotográfico de Gusinde y el efecto "mundial" de sus imágenes fueguinas, véase la tesis de Palma (2013). Aunque la autoridad académica de Gusinde sobre los fueguinos, semejante a la de Boas sobre los esquimales, atascó la discusión científica, sus registros etnográficos han sido reelaborados en notables producciones folklóricas. Al respecto, véanse las réplicas de máscaras fueguinas de Gastón Pérez Araya (2007).

17 En Historia Natural del Folklore Mason no incluye las dieciocho áreas folklóricas americanas. Hemos recuperado esta operación clasificatoria de otros de sus trabajos (Mason 1899: 48; Mason 1900: 662). Las regiones del "Fuego" y "Patagonia" se emplean como áreas de conocimiento en publicaciones de interés geopolítico y científico desde el siglo XVI. Una actualización reciente es la etiqueta "Fuego-Patagonia", empleada por el botánico magallánico Edmundo Pisano. Se trata de una simplificación igualmente útil para investigar sobre las tecnologías y conocimientos que transitan entre una y otra área (véase Morello et al. 2007). Por otra parte, el historiador y editor Carlos Vega Delgado es quien ha empleado más decididamente la etiqueta "Fuego-Patagonia" como propaganda folklórica (Vega Delgado 1995). En fin, "Fuego-Patagonia" implica una inversión de la perspectiva espacio temporal "norte-sur", importante en el estudio fenómenos como el poblamiento americano. 
¿Cómo explicar esta persistencia de Mason en Fuego Patagonia? En la época de Mason, los gobiernos de Buenos Aires y Santiago de Chile recién habían fijado la frontera que hoy separa la Patagonia de la región de Magallanes, y ésta de la Tierra del Fuego argentina. Para afirmar la instalación de la frontera se promovió el conocimiento científico de ambas áreas. De este modo, se fueron crearon colecciones, clasificaciones y exhibiciones científicas que, cuanto más rigurosas, menos lograban afirmar la diferenciación nacional. Acumularon evidencia, en cambio, de los vínculos fuego patagónicos, en tanto áreas vecinas y comunicadas. Así, los proyectos de población nacional separadas según la actual división administrativa no coinciden con las clasificaciones documentales y artefactuales en las bibliotecas y museos de la región, cuyas colecciones se comunican por debajo o por encima de la frontera "norte-sur" proyectada desde Buenos Aires o Santiago. Se trata de áreas vecinas y vinculadas tanto por ambiente como por usos, costumbres, etc., que evolucionaron como áreas de conocimiento tradicional, en el sentido de Mason.

El contexto de disputa fronteriza contribuyó entonces a la formación de científicos e instituciones de investigación regionales unitarios y, al mismo tiempo, nacionalmente motivados. Esta unidad en la frontera evitó que el conocimiento fuego patagónico se especializara al punto de separar el plano folklórico del arqueológico y del histórico. No se produjo la especialización académica que asociamos a la clasificación étnica -y que necesitaría de "personal técnico" para sus clasificaciones, como solicitaba Lévi-Strauss. Por el contrario, y quizá debido a la compleja división "étnica" que buscaba imponer la frontera desde Buenos Aires y Santiago, la ciencia en Fuego Patagonia se desenvolvió y se desenvuelve como un interminable proceso de conexión del conocimiento tradicional antiguo con el moderno.

Desde Manners and Customs of the Firelanders, los investigadores parecen haberse esforzado en buscar la conexión entre el pasado y el presente de cada nación. Dado que la frontera divide artificialmente un solo territorio, la isla Tierra del Fuego, ésta obliga a los fueguinos argentinos a pasar por Magallanes para conectarse con el resto del país. Por su parte, los magallánicos deben atravesar la Patagonia argentina para conectarse por vía terrestre con el resto de Chile. Conscientes de esta realidad, los inves- tigadores fuego patagónicos se esforzaron en acomodar las generalizaciones científicas a una base nacional escurridiza, cuya frontera no correspondía a lo que mostraban los registros histórico, arqueológico o folklórico.

Los militares que marcaron la frontera entre Argentina y Chile eran también científicos (como el soldado Powell que intervino en el debate de Mason y Boas, citado más arriba), o iban acompañados por ellos. Gente que producía clasificaciones científicas, y que se disputaba informaciones y hallazgos con comisiones científicas de otras nacionalidades.

En estas clasificaciones nacionales el indio pasó a ser un ícono popular del pasado, un folk representable de múltiples maneras gracias a las nuevas herramientas de propagación del conocimiento. Es entonces cuando la clasificación étnica surge para acomodar la evidencia científica a la imaginación nacional del pasado. El entusiasmo con que se vivió aquél nuevo ambiente de imprentas, rollos de films y telégrafos disponibles para la ciencia nacional, condujo a menudo a los científicos a inventar etnias y pasados más rápido de lo que se los podía conocer:

"El único asunto de interés sobre los fueguinos en los tres artículos anteriores (Viaje a la Patagonia austral, red. p. 459, 2ed., p. 461; Apuntes sobre las tierras patagónicas p. 201; Patagonia: Resto de un antiguo continente sumergido, p. 109), es el uso constante del autor [Moreno] de la expresión O'onas en lugar de Onas. Su razón para emplear esta expresión no es argumentada, y tampoco lo es su uso (en las mismas páginas de los dos primeros artículos) del nombre tribal 'Elisalá'as' (= ¿Elizabeth Islanders?)" (Cooper 1917: 113).

Se advierte en esta crítica el entusiasmo clasificatorio que señalamos. Y que es étnico y nacional a la vez. Anticientífico, sin duda.

Las áreas de conocimiento tradicional de Fuego y Patagonia se han ido definiendo, de este modo, en la oposición de intereses políticos y científico-propagandísticos sobre dichas áreas. En sus territorios fuego patagónicos, Chile y Argentina promovieron desde el comienzo la ciencia natural.

La intermitente tensión fronteriza ha impedido, a pesar 
de los misioneros cristianos y los sacerdotes-antropólogos, el surgimiento de una clasificación étnica que supere la frontera. Es decir, una clasificación que pudiera adherirse a la memoria de una sola nación colonizadora. Sin querer, la frontera artificial impuesta en territorios geográfica y culturalmente conectados, ha estimulado entre los investigadores regionales preguntas científicas sobre el ingenio con base artesanal o artefactual.

$\mathrm{Al}$ respecto cabe indicar que el área del Fuego muestra una orientación distinta de la representación geográfica nacional ("Norte-Sur"). Siguiendo la historia natural de Mason, el área del Fuego está orientada por el tráfico desde y hacia el Polo, y las distintas estaciones de aprovisionamiento de dicho tráfico. La isla Keppel, ocupada de manera experimental con población fueguina y donde se produjo el informe Manners and Customs of the Firelanders, fue también un establecimiento ganadero que aprovisionaba el tráfico al Polo. La logística del área del Fuego es la de estas stations o estancias de crianza de ganado, que desde las Falkland se expandieron a Magallanes y Tierra del Fuego. Rápidamente la trashumancia hacia el Polo y su economía sustituyeron a la economía trashumante de los antiguos habitantes fuego patagónicos. El área del Fuego se define entonces por el tráfico entre los archipiélagos magallánico, fueguino y falklander, a pesar de que las Falkland no figuran en el área de Fuego designada por Mason. Esta definición se observa mejor al girar la representación "Norte-Sur" de los mapas, y con ella la orientación de la frontera nacional, con la que habitualmente se imaginan las áreas de Fuego y Patagonia.

Como indicamos, la frontera ha estimulado, en lugar de limitar, el razonamiento científico de los investigadores. Y es este estímulo, precisamente, un motor en la búsqueda de identidades y fronteras de las poblaciones aborígenes en el área del Fuego.

El debate sobre una supuesta etnia, resultado del cruce entre canoeros fueguinos y cazadores patagónicos, es útil para concluir sobre la vigencia del área del Fuego en tanto área de conocimiento tradicional, donde se rozan intermitentemente la clasificación científica con base artesanal y el entusiasmo nacional por el aborigen.

La etnia en cuestión fue concebida concretamente como un "accidente étnico" por el sabio magallánico Mateo
Martinic. Con esta expresión Martinic conceptualizó a los guaicurú, un pequeño grupo mestizo de canoeros que vivía sometido a los cazadores terrestres en el istmo de Brunswick (Estrecho de Magallanes). Lo anterior lo sabemos por las noticias históricas de los guaicurúes -que corresponden todas al siglo XIX.

Al referirse a ellos como un accidente étnico, Martinic discutía la "hipótesis ingeniosa, sin duda, pero inaceptable" (Martinic 1984: 67) del sabio patagónico Rodolfo Casamiquela, quien clasificó a los guaicurúes como una nueva etnia fuego patagónica. En su artículo "Bosquejo de una etnología de la Patagonia austral", Casamiquela anuncia que los guaicurúes eran en realidad los agongures, agoures, awurwur, aawurwur o awurwan, aire o airre, representados en la lengua de los cazadores terrestres o aonikenk (según las fuentes históricas y los informantes etnográficos). A continuación, Casamiquela asoció este supuesto etnónimo al topónimo de una laguna magallánica y con eso bastó para confirmar su invento étnico ${ }^{18}$. Bautizó como airre a un "grupo netamente metamórfico de tehuelches meridionales australes y canoeros occidentales" (Casamiquela 1991: 60). Con esta clasificación Casamiquela completaba un singular panorama del poblamiento patagónico, imaginado a través de los ríos. Según el sabio, los ríos habrían actuado como filtros, tal como se organiza la visión en un programa de edición de fotos. El mismo Estrecho de Magallanes era, en su esquema, "un río más, gigantesco, aunque de agua salada". De esta imaginación resultaron dos tipos de pueblos, los "hídricos", o canoeros, y los "hidrófugos", o cazadores terrestres (Casamiquela 2003: 27) ${ }^{19}$. Los airre o guaicurúes serían la más austral de las etnias hídricas. Así figuran en un "mapa étnico hacia el año 1700" publicado por Casamiquela en su Bosquejo... y sobre el que escribió también: "Islas Malvinas (Arg.)" (1991: 67).

18 Este tipo de ajustes los aplicó en otros ámbitos de sus investigaciones, como el parentesco, donde también "Casamiquela realizó inferencias, forzando la similitud entre los nombres propios y las fonéticas hasta obtener los resultados deseados", (Vezub 2007: 169).

19 Aunque Casamiquela habla de "hidrófilos" e "hidrófobos", seguimos aquí la distinción "hídricos" e "hidrófugos" de Julio Vezub (comunicación personal), pues suprime el supuesto psicológico de Casamiquela, conservando no obstante el tropismo de la distinción. 

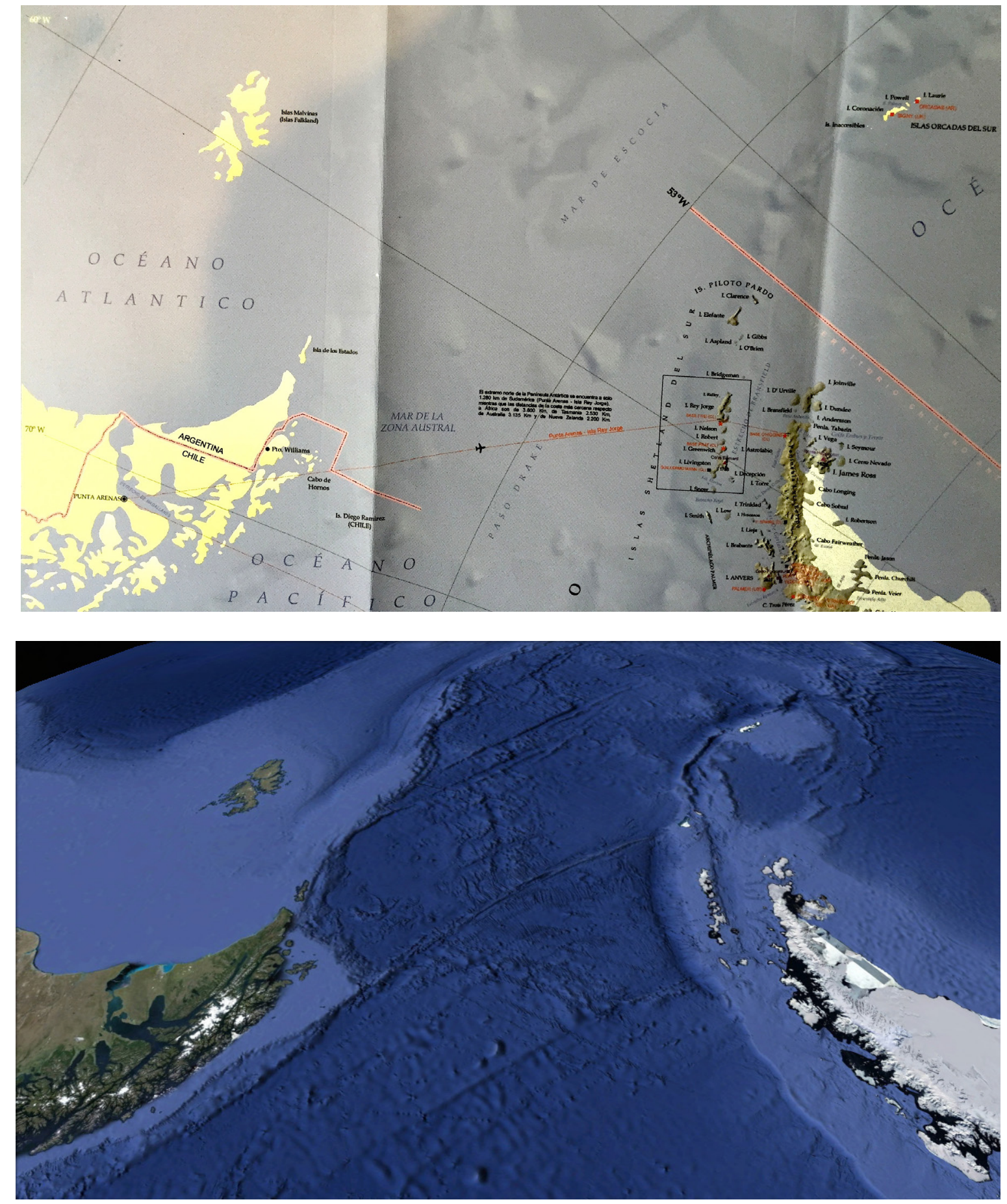

Figuras 7 y 8. Inexactitud de la imaginación "norte-sur": situación del área del Fuego respecto del Polo (imágenes extraídas del mapa rutero Compass 2010 y de Google Earth respectivamente). 
No es necesario que republiquemos estas imágenes para evidenciar la ingeniosa imaginación nacional del sabio patagónico. Por la misma razón, cuando el entusiasmo étnológico de Casamiquela avanzó sobre el área de conocimiento del sabio magallánico Martinic, la ocurrencia de un roce científico, de un accidente étnico o etno-nacional, era altamente probable. Cabe mencionar que la cuasi guerra por las islas del canal Beagle (1978) y la guerra de las Falkland/Malvinas (1982) fueron también accidentes etno-nacionales. Accidentes evitables si se hubiesen descartado a tiempo ingeniosas hipótesis nacionalistas como la que criticó, con fundamento, Martinic:

En efecto, la existencia o inexistencia de poblaciones aborígenes como los guaicurúes del área del Fuego, vistas desde la disputa entre clasificación artesanal y clasificación étnica, muestran el entusiasmo por conectar la población moderna con la antigua. En el debate que presentamos se advierte cómo la ciencia al servicio de la soberanía estimula el pasado de magallánicos, fueguinos y falklanders. Estos últimos podrían, siguiendo la lógica étnica, considerarse aborígenes de las Falkland y súbditos de Londres -o del gobierno de Buenos Aires si éste hubiese ganado la guerra de 1982-, tal como los canoeros guaicurúes fueron súbditos de los cazadores terrestres en tiempos de la colonia metropolitana de Punta Arenas ${ }^{20}$.
A la inversa, el accidente guaicurú muestra el devenir ideológico de la clasificación étnica, cuando ella es extraída del ambiente geográfico y de la memoria regional donde se descubre ésta o aquella etnia. Al igual que Boas, Casamiquela trasciende esta doble dimensión por la vía de una especulación psico-lingüística. La etnia surge como un acomodo a la imaginación de la nación que

20 Nuestra apreciación respecto del accidente guaicurú se basa en un cuadro con las fuentes históricas donde aparece dicho etnónimo publicado por Martinic (2008: 937) -más de veinte años después de su discusión con Casamiquela. "Guaicurú" designa una política poblacional, practicada por los tehuelches históricos (aonikenk) con los canoeros marítimos (kawéskar), durante los siglos de contacto post colonial con mapuche y europeos. Esta práctica se adhirió a la cultura tehuelche por la impresión que dejó en ella las relaciones de servidumbre que practicaban estos pueblos y que tanto Chile como Argentina también practican. Esta relación de esclavitud o servidumbre se expresa en la denominación "guaicurú" de los tehuelches para sus canoeros domesticados. El hecho de que los modernos guaicurú del Chaco paraguayo, denominados así tempranamente por los españoles, sean todavía un pueblo de a caballo con esclavos de grupos vecinos, es otra pista en la dirección señalada. Un cuadro reciente de familias lingüísticas del Chaco muestra, por último, la heterogeneidad de pueblos que cubre la denominación "guaicurú" (Richard 2012: 38 cuadro 1).

Referencias históricas sobre el grupo humano presuntamente Mestizo del istmo de Brunswick

\begin{tabular}{|l|l|l|l|}
\hline Informante & Lugar 0 comarca & Denominación & Número \\
\hline Mac Douall 1833 & No se menciona & Zapoliens & No se da \\
\hline Arms y Coan 1833-34 & Port Famine & Supalios & Menos de 100 \\
\hline Fitz Roy 1834 & Cerca de los golfos de Otway y Skyring & Zapallos & No se da \\
\hline D'Urville 1838 & Puerto Peckett & Pecherais & Una cincuentena \\
\hline Roquemaurel 1838 & Puerto Peckett & Pecherais & No se da \\
\hline Gourdin 1838 & Puerto Peckett & No se da & No se da \\
\hline Smith 1844 & Bahía Laredo-Cabo Negro & (Fueguinos) & No se da \\
\hline Dunne 1845 & Terrenos de los patagones & Guaicurúes & No se da \\
\hline Pasolini 1845 & Laguna Cabo Negro & Indios de la Laguna & Una tribu \\
\hline ¿Philippi? 1847 & Bahía Laredo & Laredos & No excede 200 \\
\hline Mardones 1848 & Cabo Negro & Guaicurúes & 29 \\
\hline Betelu 1849 & Cabo Negro & Oriundos de la Tlerra del Fuego & No se da \\
\hline Salas 1852-53 & Cabo Negro & Guaicures & Pequeña tribu \\
\hline Schythe 1855 & Contorno del Cabo Negro & Guaicurúes & Una familia \\
\hline Catlin 1856 & Puerto Peckett & Fueguinos & Una docena \\
\hline Cox1863 & Orilla norte del Estrecho & Huaicurúes & No se da \\
\hline
\end{tabular}

Figura 9. Tabla publicada por Martinic (2008: 937) 
conquista el territorio indio. Si esto además se coloca en una cronología, lo que resulta es toda una "fantasmología etnomercantil [conceptualizada] a partir de períodos coloniales" (Fernandes 2005: 345). En este sentido, el accidente guaicurú forma parte del folklore del área del Fuego, de su delimitación en tanto área de conocimiento tradicional, dividida entre dos administraciones nacionales y sus respectivas preguntas sobre el pasado ${ }^{21}$.

Hemos empleado la expresión "sabio", en reconocimiento a la extraordinaria actividad científica tanto de Martinic como de Casamiquela, pero sobre todo para enfatizar las áreas de conocimiento tradicional que los conectaron $y$, en este caso, los opusieron ${ }^{22}$. Un reconocimiento también al ensayo de generalización, en el caso de Casamiquela, basado en el trabajo de sus antecesores (entre ellos el folklorista Milcíades Alejo Vignati y el notable etnógrafo Thomas Harrington), basado en su colección personal de cráneos, en su reflexión sobre materiales arqueológicos, arte rupestre, fuentes históricas y a su entrenamiento en lenguas aborígenes ${ }^{23}$. Reconocemos también un esfuerzo común a ambos sabios por transmitir el saber folklórico fuego patagónico a la población regional, como no ocurre con los antropólogos, historiadores, arqueólogos ni curadores metropolitanos, seguidores o herederos de Martín Gusinde o Franz Boas ${ }^{24}$.

En el caso de Martinic, además de su trabajo como historiador, arqueólogo y curador, debemos considerar su rol como máxima autoridad política de la región de Magallanes (1964-1970). Su actividad entonces se aproximó como nunca a las ideas propagandísticas de Mason en Historia Natural del Folklore, pues investido de autoridad como estaba, pudo promover la clasificación natural y cultural sobre bases regionales y científicas.

\section{* Clasificación artesanal en la frontera DEL ÁREA DEL FUego}

La supervivencia de la denominada "área del Fuego" de Mason, en tanto área de clasificaciones artesanales en lugar de étnicas, deriva de su situación de área fronteriza respecto de los centros nacionales metropolitanos y sus medios de divulgación científica y de propaganda cultural. Al estar desconectada o desfasada respecto de estos medios, el área de conocimiento cultiva una sabiduría propia, conservada y transmitida en notables investiga- ciones fuego patagónicas como la de Martinic y Casamiquela.

La deriva autoritaria del conocimiento tradicional, por otra parte, es aquél conocimiento que se estanca y atrasa cuando se desconecta del régimen autónomo o federal de biblioteca y museo en el que trabajó Mason. En el área del Fuego esto parece haberse evitado gracias a la tensión fronteriza. Identificamos en el área del Fuego una tradición científica autónoma por accidente, asociada a los distintos ensayos y errores político-poblacionales promovidos o tolerados por las metrópolis nacionales.

En Chile simplemente nunca existió el régimen federal en que surgió la clasificación artesanal de Mason (las máximas autoridades políticas y culturales de Magallanes son aún designadas desde la capital). Siendo intendente de Magallanes, Mateo Martinic colaboró con científicos naturales en la creación de una institución autónoma y unitaria en cuanto a biblioteca, museo y laboratorios experimentales (el Instituto de la Patagonia, fundado en

21 Por esta razón el área del Fuego incluye las tres divisiones administrativas, a saber, el archipiélago magallánico, el archipiélago fueguino y el archipiélago falklander o malvinero. No sólo por razones de continuidad geológica y semejanza medioambiental, sino porque en el archipiélago falklander se hicieron experimentos con población fuego patagónica (Philpott, 2009), paralelos a la ocupación chilote-chilena del Estrecho de Magallanes. Por otra parte, el desarrollo de la ciencia y de la soberanía, como indicamos, ocurre simultáneamente en Magallanes, Tierra del Fuego y las Falkland.

22 Martinic publicó su primera discusión de la hipótesis ingeniosa de Casamiquela cuando todavía no se publicaba el Bosquejo de éste. Suponemos que recibió un impreso enviado especialmente por Casamiquela.

23 Esto último, parece haberlo desviado del artefacto y la costumbre hacia clasificaciones étnicas puras (véase Rodríguez 2012: 129 nota 75). El límite meridional que trabajos como los de Martinic han opuesto a la imaginación de Casamiquela, también se verifican en la Patagonia septentrional (véase Boschín 2009: 21 nota 6).

24 Casamiquela representó el papel del sabio junto a Liliana Chertoux (la "aprendiz"), en una notable serie radiofónica titulada "Los Antiguos" y transmitida por la Radio Nacional argentina (Viedma) en 1980. La misma forma parte del Archivo Sonoro y Digital de Patagonia y Tierra del Fuego (compilado por Carlos Vega Delgado y Lorenzo Salles), disponible en la Biblioteca Municipal de Punta Arenas (CD 3 al 9). 
1969). Este régimen unitario de investigación mantuvo su autonomía hasta 1984, cuando pasó a depender del sistema universitario chileno, regulado desde la capital y que concibe la educación como un bien de consumo privado, antes que como un bien público (Ley 19.287 O de "Crédito Solidario" de 1994). Consciente de esta situación y frente a la posibilidad de desintegración de su legado, el sabio magallánico decidió publicar su propia Bio-bibliografía (Martinic 2011).

Este gesto editorial, sabio, voluntarista y orgulloso, nos refiere la vigencia del área del Fuego en tanto área de conocimiento tradicional. Área dividida por regímenes políticos distintos en cuanto a la organización de museos y bibliotecas, e impedida por tanto de organizar una clasificación étnica nacional, chilena o argentina.

La frontera fueguina produce un tipo de comunicación y de acción política que se ocupa artificialmente de un solo lado, esquivando la historia y la arqueología de la isla que la presentan como una unidad geográfica y cultural. Así, el efecto político de la frontera hace que observatorios mundiales en materia de educación popular no consideren la Tierra del Fuego como una unidad o área de conocimiento tradicional ${ }^{25}$. En el lado chileno de la isla, por otra parte, la comunicación terrestre se efectúa principalmente por rutas de ripio que han evolucionado siguiendo la discutible política hemisférica de eje "nortesur" ("extremo sur", "zonas extremas", etc.), en lugar de conectarse naturalmente hacia el Atlántico con la ruta de asfalto de la provincia argentina. Las intermitentes amenazas de guerra en el área han interrumpido, por último, la comunicación regional, ocultando el pasado y el presente común a ambos lados de la frontera ${ }^{26}$.

Todo lo anterior podría señalar al área del Fuego como una zona de padecimientos desde que se fijó la frontera. Pero desde otra perspectiva, se advierte que las provincias

25 Véase el informe de Unicef sobre la educación fueguina, que considera sólo la provincia argentina (Scasso y Pérez León 2010).

26 Los graves efectos comunicacionales de la cuasi guerra chilenoargentina de 1978 y de la guerra por las Falkland/Malvinas en 1982 sobre la población de Río Grande, han sido registrados por el historiador fueguino Roberto Chenú en un texto aún inédito (véase el capítulo "Guerra y memoria en una localidad del sur argentino (1978-1982)”, en Lorenz (2012)). y poblaciones del área han vivido en relativo aislamiento y autonomía respecto de los vaivenes económicos, políticos e ideológicos de ambos países. Hemos dicho que la frontera ha fortalecido la clasificación artesanal y el pensamiento científico folklórico autónomo (Bascopé Julio 2015). En el caso de Magallanes, desde su creación soberana como territorio chileno (1843) hasta la guerra argentino-británica (1982), la región estuvo siempre mejor comunicada con la Tierra del Fuego y las islas Falkland que con la administración chilena (Bascopé Julio 2014, 2016b). Lo anterior incluye los talleres de temporada en medios de comunicación, desarrollados en yagán e inglés en la referida estación de Keppel, donde se procesaron los citados usos y costumbres de los "Firelanders" (Bridges 1866).

Vistos de este modo, los efectos de las clasificaciones étnicas nacionales son relativos en el área del Fuego, a pesar del flujo etnólogos que llega a la región desde Santiago, Buenos Aires y otras metrópolis. Esta autonomía relativa del área se debe a su situación sub-antártica, concretamente al tráfico polar creciente en el área del Fuego y a la conexión del área con otras puertas de acceso a la Antártica (como son Tasmania o Christchurch).

Reconocemos, por último, que el rol educativo de las industrias de transporte y comunicación, cuyo folklore fascinó a Mason, no es hoy tan evidente como lo era en el siglo XIX. Mason fue, en este sentido, un entusiasta de su época industrial, aquella donde al dominio de los mares y a la aceleración de la comunicación terrestre, se sumó la conquista del espacio aéreo. Hoy, en cambio, ya no se trata de la domesticación de la luz eléctrica o de los futuros beneficios de la telecomunicación, pues la edad de piedra, la del barco trasatlántico y la del satélite se superponen tanto en la Antártica como en el área del Fuego (así como en otros "confines" de Argentina, Chile e incluso de los Estados Unidos).

Un puente que reconecte artificialmente la Patagonia con la Tierra del Fuego ya no se construyó (ni siquiera se ha concluido la ruta de asfalto entre Punta Arenas y Ushuaia, desincentivada por la frontera que divide la isla). Y no ocurrirá antes de que la velocidad de las comunicaciones aéreas haya relativizado su importancia. Es decir, que tras la época marítima del descubrimiento del Estrecho de Magallanes no siguió la época del avión. Tal vez un 
tren turístico transnacional comunique un día los atractivos de El Chaltén y Puerto Natales, pero ésta será, sin duda, una época distinta a la de Mason. Porque desde la era del caballo adoptado por los cazadores patagónicos hasta la colonización con trenes, barcos y telégrafos de su territorio, lo que sucedió fue un caos de espacios conquistados y de imaginación histórica impuesta: así vista la instalación del estado nacional en áreas como la del Fuego fue un brutal collage de épocas.

La civilización tele-comunicada, por otra parte, representa ahora un atasco o un colapso para la ciencia, si se la compara con la época de Mason. Un atasco en cuanto a la divulgación del conocimiento científico natural en zonas saturadas de comunicación o en vías de saturación. La existencia, por ejemplo, de una sobrepoblación de teléfonos móviles que tanto en Chile como Argentina iguala o supera las cifras demográficas de cada país, sin garantizar con ello ningún progreso social, es una distinción importante entre nuestro ambiente explotación de las comunicaciones y el de Mason. La industria comunicacional evolucionó junto con la economía mercantil, tomando un camino diferente al proyecto educativo nacional que se imaginó en el siglo XIX. Hoy la comunicación entre las personas y los pueblos es, en parte, un negocio y no el advenimiento de una era, como se creyó y se actuó en la época de Mason.

Por último, lo que se presenta como un caos de épocas para la civilización es experimentado y pensado de otro modo en áreas fronterizas, marginales respecto de la comunicación científica metropolitana. Se trata de gente de grupos étnicamente clasificados que pensaron el caos, desde el caos de guerras y conquistas coloniales, previo a las clases étnicas de Boas o Lévi-Strauss y a las polémicas etnonacionales como la de Martinic versus Casamiquela.

Nos referimos a una multitud de antropólogos o "filósofos vestido" (según Mason) que van siendo descubiertos precisamente cuando distinguimos entre la clasificación étnica y la clasificación artesanal ${ }^{27}$. Artesanos/as de pueblos originales como los falklanders, o aborígenes como los araucanos, con teorías culturales propias y medios para divulgarlas. Personajes casi de ficción -al momento de ser descubiertos-, que surgen en los márgenes de las poblaciones explotadas por la tele-comunicación. Usan vestidos distintos a los civilizados y teorizan sobre razas hasta entonces desconocidas:

"Sistema rudimentario de telégrafo fue empleado por tribus araucanas".

Lo aseguró ayer a La Nación José Inalaf Navarro, presidente de la Alianza Cultural Araucana.

\section{Los araucanos se organizan $[\ldots]$}

"La raza aborigen -aseguró- se comunicaba entre ella mediante ondas sonoras que transmitían a través de la tierra, y tenían centros de recepción que denominaban "RENU", similares a los "tambos" de los incas". Agregó que estas comunicaciones eran posibles también entre las tribus de Chile y las de Argentina, y que "permitieron un intercambio cultural y artístico que logró resistir con toda energía la invasión española". "La Alianza Cultural Araucana - nos expresa el señor Inalaf- cuenta con los instrumentos jurídicos y administrativos, que tienden a reivindicar al pueblo araucano. En su sede social de Puente 765 funcionan bibliotecas, servicio médico y social. Su establecimiento pretende hacer concebir a sus afiliados una concepción digna y pura, inspirada en los principios en que descansó la estructura primitiva del pueblo araucano. El amor a la tierra, a la patria y la superación es el trípode en que descansan los principios fundamentales de nuestra organización" (Diario La Nación, 1948) ${ }^{28}$.

Cuando Mason definió sus dieciocho áreas de conocimiento tradicional americanas no incluyó en ellas a la actual Región de la Araucanía. Hizo algo razonable. No clasificó a los araucanos de Chile como pueblo folklórico

27 "Cualquiera sea nuestra teoría sobre la manera, el lugar o el tiempo en que el hombre advino en este planeta, todas coinciden en que al principio era un ser sin hogar, sin ropa, sin habilidades ni experiencia, y que por el ejercicio de sus facultades se convirtió en el filósofo vestido. Hay un sentido en el cual puede decirse que la raza se inventó a sí misma, actuando contra la Naturaleza a menudo, otras veces con ella, pero siempre del naturalismo a la artificialidad. [...] Estamos siempre escuchando a los sociólogos decir que el hombre no inventa costumbres, sino que cae en ellas. Garanticemos que noventa y nueve de cada cien sigan la costumbre, y garanticemos además que cada uno de nosotros siga a su líder siempre hasta la milésima vez. Es el acto singular que cada uno origina, uno en cien o en mil, lo que constituye el progreso del mundo" (Mason 1902a: 20).

28 Diario La Nación (Santiago de Chile), 11 de mayo de 1948, p. 2. Citado en el Libro Diario del Presidente de la Federación Araucana (Aburto Panguilef 2013: 819). 
o del pasado, pues se trataba de una nación aborigen (la actual nacionalidad mapuche), con un sistema de comunicaciones que en la Argentina llegó a organizarse como una confederación (De Jong 2009) y que hasta fines del siglo XIX mantuvo su independencia respecto del Estado chileno. A partir de entonces conocerían lo peor del caos de épocas. Los araucanos fueron expulsados de la Argentina y perdieron su territorio en Chile, fueron puestos en reservas comunitarias, tal como los indios del país de Mason. Homogéneamente se empobrecieron y convirtieron en etnia. Esto fue denunciado por los sabios araucanos que manejaban la imprenta ${ }^{29}$, pero fue insuficiente para evitar la llegada de etnólogos que los estudiarían como etnia del pasado.

Aunque la validez histórica del sistema telegráfico de las tribus araucanas sea discutible, hemos recuperado el ejemplo pues expresa la realidad científica y propagandística de organizaciones fronterizas como la antigua Alianza Cultural Araucana o el Instituto de la Patagonia en Magallanes. Comparten la misma visión histórico natural del Instituto Smithsonian o del museo de ciencias de La Plata. Se trata de organizaciones con un formato de investigación y de divulgación del conocimiento relativamente autónomo, tal como la orgánica de oficinas con electricidad e imprentas de Mason (la destacada Government Printing Office).

Por circunstancias distintas, en estas organizaciones se dio la colaboración entre ciencias naturales, investigación histórica, arqueológica, además de la experimentación artesanal. Este formato de investigación y divulgación fue hasta hace poco el del Instituto de la Patagonia. Y es en organizaciones con este formato donde el caos de épocas puede canalizarse de manera original, cruzando y trenzando conocimientos, y donde uno en cien o en mil de estos cruces, constituye un progreso.

La ciencia de Mason sobrevivió al margen de su época, entonces, a pesar del olvido académico en que cayó el curador del Smithsonian ${ }^{30}$. Sobrevivió en situaciones fronterizas como la del área del Fuego o de la Araucanía. La ciencia de Mason, a diferencia de la de Boas o LéviStrauss, no recluta seguidores en torno a ésta o aquella teoría de la cultura. Por el contrario, sus cruces y experimentos disciplinarios complican al líder de cualquier culto antropológico. Y a sus seguidores. La ciencia de Mason será siempre crítica de la filosofía vestida, aunque esta provenga de un cacique, de un cura o de un antropólogo ${ }^{31}$. Se trata de una ciencia que al divulgarse se vuelve propaganda político-cultural, tal como la practicaron Inalaf Navarro o Isabelo de los Reyes (ver supra). Una ciencia folklórica, en fin, cuyo entusiasmo nacional y científico corresponde a otra época, pero que es perfectamente replicable con artefactos del siglo XXI.

29 "La radicación en comunidad [indígena] ha dado resultados funestos porque se igualó injustamente a todos y de aquí la lucha del más rico contra el más pobre; éste exige lo que la ley le dio y aquel no puede comprender se le haya quitado lo suyo para darlo a éste. Este fue un golpe premeditado al parecer contra los indios más pudientes, a sus fortunas que quizás les habrían servido para educar sus hijos, quienes habrían defendido a su raza de tanto abuso. Mataron pues a los ricos e hicieron como los gobiernos despóticos que matan al obrero

30 Pensadores políticos como Benedict Anderson e Ithiel de Sola Pool en Estados Unidos, o Paulo Freire en Brasil, han compartido y propagado el entusiasmo nacional y científico de Mason. Por su parte, la antropología del pacífico-antártico practicada por el capitán magallánico y general de ejército Ramón Cañas Montalva, es la mejor manifestación nacional chilena que conocemos, en cuanto a la orientación natural, científica y política del área de Fuego. Consúltese al respecto "Los hombres y el territorio en el trascendente devenir geopolítico de Chile" (Cañas Montalva 1962-1973).

31 "No es tiempo de que existan seres tan atrasados, y menos aún que ni siquiera se preocupan de su arreglo personal. El que suscribe ha sido testigo de haber visto en congresos y reuniones araucanos a caciques vestidos en tal forma y con tal aspecto de miseria y abandono, que no debía existir de parte de ellos. Aquí mismo en Santiago no es raro ver algunos de estos ejemplares", José Inalaf Navarro, "El Caciquismo es factor negativo en la economía indígena”, 12 de julio de 1941 (fotocopia de prensa entregada por el antropólogo Roelf Foerster al centro de estudios mapuche Liwen, sin precisar el periódico, y cedida a nosotros por Claudio Cratchley, otro activista de dicho centro). Inalaf se emparenta aquí con el pensamiento político de Manuel Mañkelef (1915). Al respecto, hemos publicado La invasión de la tradición: lo mapuche en tiempos culturales (Bascopé Julio 2012). 


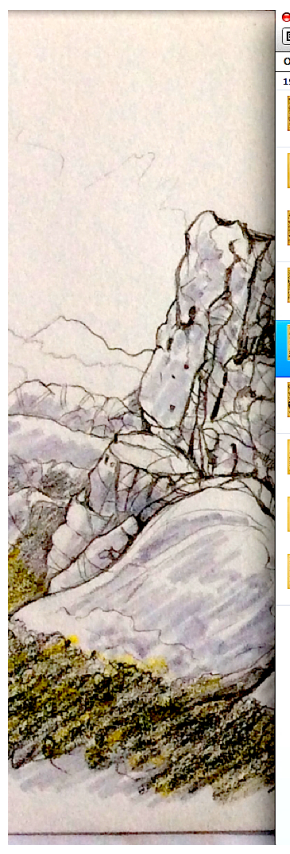

国- Q⿴囗十心

81 de 880$)$ T

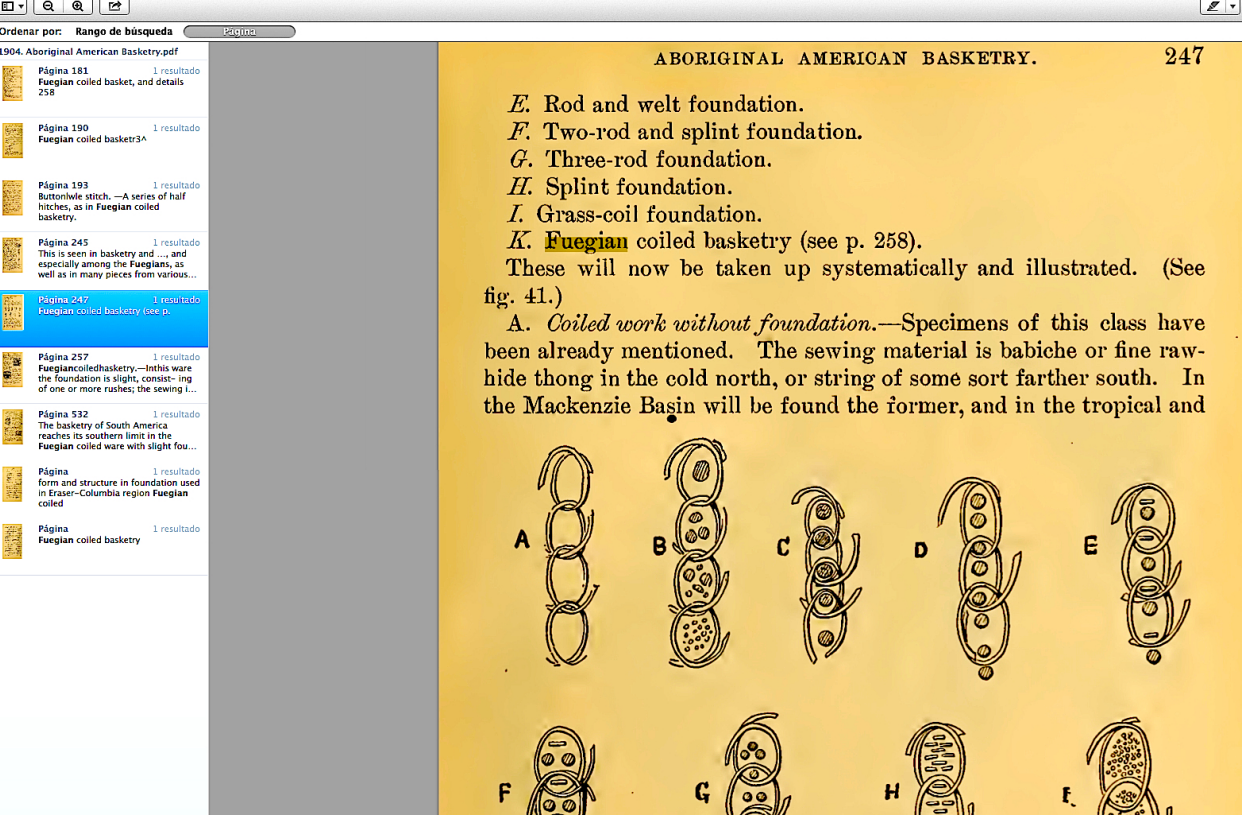
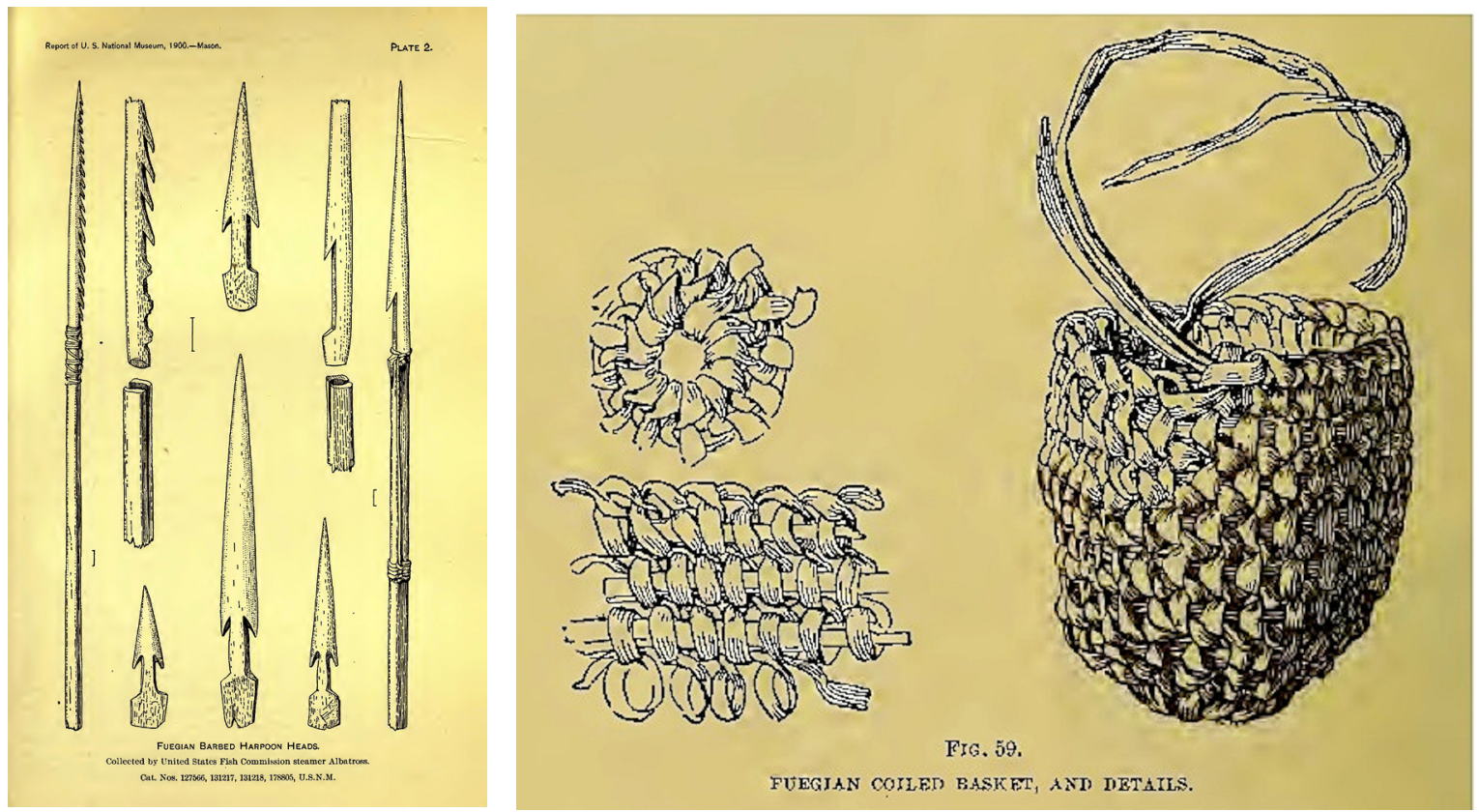

Figuras 10, 11 y 12. Colección de arpones, variaciones de tejido enroscado de cestería, esterillas y mochilas y cesto de transporte fueguino estudiados por Otis Mason, referidos en Cooper (1917: 111) y halladas vía OCR (Reconocedor Óptico de Caracteres) durante nuestra pesquisa. En los dibujos de sus informes para el museo, Mason practicaba una escritura hipervinculada: replicaba la etiqueta (no evidente) de quien colectó el objeto, incluyendo el paradero donde fue colectado y el código de clasificación de bodega en el museo. 


\section{* Conclusión}

Nuestro artículo presenta un debate en torno a La Historia Natural del Folklore, un estudio publicado en 1891 por el curador Otis Mason. En primer lugar, introducimos al lector en las actividades de inteligencia y propaganda de Mason, a través del museo, y definimos su clasificación artesanal, basada en exhibición artefactual. También definimos la perspectiva política de la ciencia folklórica de Mason. Luego analizamos un debate sobre exhibiciones museográficas y clasificación étnica versus artesanal. Por último, recuperamos la vitalidad nacional y científica de La Historia Natural del Folklore para testear, de acuerdo a nuestros propios conocimientos, una de las áreas curatoriales de Mason: el área de conocimiento tradicional del Fuego.

En las páginas precedentes presentamos al lector la clasificación artesanal, relevando el tipo de ciencia que Mason generalizó en "áreas de conocimiento tradicional" americanas. Dicha ciencia es la antropología y está compuesta por arqueología, historia y folklore.

Quisimos destacar igualmente el trabajo de divulgación y propaganda científica de Mason, orientado a la transmisión del conocimiento tradicional a la población de su país. Sus actividades en el museo nacional de Washington, hemos visto, le plantearon preguntas sobre las posibilidades de clasificación de los artefactos en exhibición. En ese contexto presentamos su clasificación artesanal, basada en los artefactos colectados para el museo con én- fasis en el ambiente de donde provienen, y analizamos el debate entre dicha clasificación y la clasificación étnica. Vimos a continuación cómo la antropología interesada en la clasificación de mitos indígenas complejizó la clasificación étnica, procediendo a una desconexión entre la cultura y el ambiente en el que ésta se registra o se colecta. Así, las teorías de la cultura de base clasificatoria formaron un campo académico de debate, el cual se alejó del conocimiento científico producido en sintonía con una población determinada. En la última parte de este trabajo, presentamos un área marginal de la antropología académica, el "área del Fuego", en el que por circunstancias especiales la clasificación artesanal de Mason no dejó de practicarse.

\section{* Agradecimientos}

Agradezco a Yanina González, Julieta Gómez Otero, Florencia del Castillo Bernal, María Teresa Boschín, Joan Spruce, Antonio Deza González, Alfredo Prieto Iglesias, Juan Carlos Muñoz Alegría, Iván Peña Jonshon, Samuel García Oteiza, Marcos Sourrouille, Branko Marinov Martinic, Claudio Cratchley y Alejandro Garcés, por los enriquecedores intercambios que sostuvimos durante la elaboración de este trabajo. Agradezco igualmente a los participantes del curso "Metodologías, archivos, fuentes y formatos de historia indígena fuego patagónica", que realicé junto a Julio Esteban Vezub en la Universidad Nacional de la Patagonia San Juan Bosco, Trelew, Chubut, entre septiembre y noviembre de 2015. 


\section{* Referencias citadas}

ABURTO, M. 2013. Libro Diario del Presidente de la Federación Araucana. Ediciones CoLibris, Santiago, Chile.

ABEL, M. 1977. Boas in the National Museum: An Addendum. American Anthropologist 79 (2): 442.

ANALES DE DESCLASIFICACIÓN. 2005. "Para los cien años de Sobre las formas primitivas de clasificación. La derrota de la desclasificación (homenaje crítico)". En Anales de Desclasificación 1 (1): 21-49.

ANDERSON, B. 1983. Imagined communities: Reflections on the origin and spread of nationalism. Verso Books, Londres, Inglaterra.

ANDERSON, B. 2005. Under Three Flags. Anarchism and the AntiColonial Imagination. Verso Books, Londres, Inglaterra.

BASCOPÉ, J. 2009. La invasión de la tradición: lo mapuche en tiempos culturales. Ediciones CoLibris, Santiago, Chile.

BASCOPÉ, J. 2014. La soberanía, los medios y las Falkland. Proyección magallánica. El Fortín del Estrecho 120:30-38.

BASCOPÉ, J. 2015. Documentos inéditos para la historia de Magallanes: «La autonomía y Magallanes». Magallania 43 (2): 205-221.

BASCOPÉ, J. 2016a. "El encantador de yaganes. Entrenamiento de nativos fueguinos en la isla Keppel, 1854-1869". Ensayo primer premio del concurso "La cuestión Malvinas: a 50 años de la resolución 2065" organizado por el Consejo Latinoamericano de Ciencias Sociales. Disponible en biblioteca.clacso.edu.ar/clacso/becas/20160218030932/EncantadorUpload.pdf.

BASCOPÉ, J. 2016b. Línea Kosmos del baqueano polar: reporte de un viaje a tierras falklander. El Magallanes 26.398: 10-11.

BOAS, F. 1887a. The ocurrence of similar inventions in areas widely apart. Science 9:485-486.

BOAS, F. 1887b. Museums of ethnology and their classification. Science 9: 587-589.

BOAS, F. 1887c. Museums of ethnology and their classification. Science 9: 614 .

BOAS, F. 1908. Otis Tufton Mason. Journal of American Folklore 21 $(82): 362$

BOSCHÍN, M. 2009. Tierra de Hechiceros. Arte indígena de Patagonia Septentrional argentina. Universidad de Salamanca, Salamanca, España.
BRIDGES, T. 1866. Manners and Customs of the Firelanders. En $A$ Voice for South America, vol. 13, pp. 181-184 y 201-214. Londres.

BUETTNER-JANUSCH, J. 1957. Boas and Mason: Particularism versus Generalization. American Anthropologist 59 (2): 318-324.

CAÑAS, R. 1962-1973. Los hombres y el territorio en el trascendente devenir geopolítico de Chile. En Revista Geográfica de Chile Terra Australis, vol. 20, pp. 62-85. vol. 21, pp. 51-77 y vol. 23, pp. 52-71.

CASAMIQUELA, R. 1991. Bosquejo de una etnología de la Patagonia austral. Waxen 3: 41-80.

CASAMIQUela, R. 2003. Poblamiento indígena de la Patagonia. Cuadernos de Historia Patagónica 1: 17-46.

CLIFFORD, J. 1988. The Predicament of Culture. Universidad de Harvard, Cambridge, Estados Unidos.

CLIFFORD, J., MARCUS, G. 1986. Writing Culture. Universidad de California, Los Angeles, Estados Unidos.

COOPER, J.M. 1917. Analytical and critical bibliography of the tribes of Tierra del Fuego and adjacent territory. Bureau of American Ethnology, Washington, Estados Unidos.

DE JONG, I. 2009. Armado y desarmado de una confederación: el liderazgo de Calfucurá en el período de la organización nacional, Quinto Sol 13: 11-45.

DE SOLA POOL, I. 1984. Technologies of Freedom. Universidad de Harvard, Cambridge, Estados Unidos.

DORSEY, J. 1892. Siouan Onomatopes. American Anthropologist 5 (1): $1-8$.

FERNANDES, B. 2005. Compte-rendu analytique et extraits de Cita Sempruna Warisan Sejarah (L'idéalisme, héritage de l'Histoire). Ouvrage de Syed Hussein Alatas. Anales de Desclasificación 1 (1): 335-345.

FREIRE, P. 2004. [1969]. La educación como práctica de la libertad. Siglo XXI, Buenos Aires, Argentina.

HERZOG, W. 2012. Conquista de lo inútil. Blackie Books, Barcelona, España.

HINSLEY, C., HOLM, B. 1976. A Cannibal in the National Museum. The Early Career of Franz Boas in America. American Anthropologist 78 (2): 306-316. 
HRDLICKA, A. 1908. Otis Tufton Mason. Science 28 (726): 746-748.

LÉVI-STRAUSS, C. 1958. Anthropologie Structurale. Édition Plon, París, Francia.

LORENZ, F. 2012. Unas islas demasiado famosas. Editorial Capital Intelectual, Buenos Aires, Argentina.

MARTINIC, M. 1984. Los guaicurúes, ¿un grupo racial definido o un accidente étnico?. Anales del Instituto de la Patagonia 15: 63-69.

MARTINIC, M. 2008. "Convivencia kawéskar-aónikenk en el istmo de Brünswick, Patagonia Austral, Chile. Un caso de mestizaje cultural", en Levantando piedras, desenterrando huesos... y develando arcanos. Actas de las VI Jornadas de Arqueología de la Patagonia: 927-940. Punta Arenas.

MARTINIC, M. 2011. Bio-Bibliografía. La Prensa Austral, Punta Arenas, Chile.

MANÑKELEF, M. 1915. Las Tierras de Arauco. Imprenta El Modernista, Temuco, Chile.

MASON, O. 1891. Natural History of Folklore. The Journal of American Folklore 4 (13): 97-105.

MASON, O. 1896. Primitive Travel and Transportation. Government Printing Office, Washington, Estados Unidos.

MASON, O. 1899. Aboriginal Zootechny. American Anthropologist 1 (1): 45-81 1900 .

MASON, O. 1899. Traps of the Amerinds. A Study in Pshycology and Invention. American Anthropologist 2 (4): 657-675.

MASON, O. 1902a. The Origins of Invention: A Study of Industry Among Primitive Peoples. The Walter Scott Publishing, Nueva York, Estados Unidos.

MASON, O. 1902 b. Aboriginal American Harpoons: A Study in Ethnic Distribution and Invention. Government Printing Office, Washington, Estados Unidos.

MASON, O. 1902c. Directions for Collectors of American Basketry. Government Printing Office, Washington, Estados Unidos.

MASON, O. 1904.Aboriginal American Basketry: Studies in a Textile Art Without Machinery. Government Printing Office, Washington, Estados Unidos.

MORELLO, F., MARTINIC, M., PRIETO, A., y BAHAMONDE, G. 2007. Arqueología de Fuego-Patagonia. Levantando piedras, desenterrando huesos... y develando arcanos. Ediciones CEQUA, Punta Arenas, Chile.
NAVARRO, P. 2008. El proceso de construcción social de la región de Nahuel Huapi en la práctica simbólica y material de Exequiel Bustillo (1934-1944). Pilquén 9: 1-14.

PALMA, M. 2013. Fotografias de Martín Gusinde en Tierra del Fuego (1919-1924). Universidad Alberto Hurtado, Santiago, Chile.

PAVEZ, J. 2003. Mapuche ñi "nütram chilkatun/ Escribir la historia mapuche: Estudio posliminar de Trokinche müfu ñi piel. Historias de familia. Siglo XIX. Revista de Historia Indígena 7: 7-53.

PAVEZ, J. 2012. Disciplina científica colonial y coproducción etnográfica: las expediciones de Martín Gusinde entre los yámana de Tierra del Fuego. Magallania 40 (2): 61-87.

PÉREZ, G. 2007. Catálogo. Réplicas de máscaras. Ceremonia del Hain. Cultura Selknam. La Prensa Austral, Punta Arenas, Santiago.

PHILPOTT, R. 2009. Keppel: A South American Missionary Society Settlement in the Falkland Islands, 1855-1911. An Archaeological and Historical Survey. Falkland Islands Museum and National Trust and Liverpool National Museum, Stanley, Islas Malvinas.

PRIETO, A. 2013. Cueva del Milodón: publicaciones desde 1899 a 1996. Universidad de Magallanes, Punta Arenas, Chile.

PRIETO, A., CÁRDENAS, R. 1999. Entre los fueguinos: cuna reacción antievolucionista de la escuela histórico-cultural?. Anales del Instituto de la Patagonia 27: 89-98.

RICHARD, N. 2008. Les chiens, les hommes et les étrangers furieux. Archéologie des identités indiennes dans le Chaco boreal. Tesis de doctorado, EHESS, París, Francia.

RODRÍGUEZ, M. 2010. De la "extinción" a la autoafirmación: procesos de visibilización de la Comunidad Tehuelche Camusu Aike (Provincia de Santa Cruz, Argentina". Tesis de doctorado, Universidad de Georgetown, Washington, Estados Unidos.

SALLE, L., VEGA, C. 1998. Archivo Sonoro y Digital de Patagonia y Tierradel Fuego. Fondart, Punta Arenas, Chile.

SAMMAR, V. 1995. Artifactually induced ERP classification of form and color attributes: A refutation of 'Neuroelectric concepts: Form-Color Classification' by William Hudspeth (1993). Brain and Congnition 27: 98-111.

SCASSO, M., PÉREZ LEÓN, N. 2010. Tierra del Fuego: la educación en cifras. Informe para Unicef Argentina. Disponible en http://www.unicef.org/argentina/spanish/tierra_del_fuego.pdf

SENNET, R. 2009. El Artesano. Editorial Anagrama, Barcelona, España. 
SIDNEY, E. 1886. The Outcast Child. The Folk-Lore Journal 4 (4): 308-349.

STOCKING, G. 1966. Franz Boas and the Culture Concept in Historical Perspective. American Anthropology 68 (4): 867-882.

TEIT, J. 1898. Traditions of the Thompson River Indians of British Columbia. American Society of Folklore, Boston, Estados Unidos.
TRUjILLO, C. 2000. "In Their Own Words: The Folk Literatture of South American Indian Series", en Documenting Movements, Identity, and Popular Culture in Latin America. Seminar on the Acquisition of Latin American Library Materials: 121-129. Universidad de Texas, Austin.

VEGA, C. 1995. Sombras de Fuego-Patagonia / Patagonia Fire Shadows. Atelí, Punta Arenas, Chile.

VEZUB, J. 2007. Crítica de los «panoramas etnológicos» de Patagonia. Etnia 48: 161-186. 